\title{
VABCD Regimen
}

National Cancer Institute

\section{Source}

National Cancer Institute. VABCD Regimen. NCI Thesaurus. Code C161999.

A chemotherapy regimen consisting of vinblastine, doxorubicin, bleomycin, lomustine (CCNU), and dacarbazine that may be used in the treatment of refractory Hodgkin lymphoma (HL). 